\title{
EVIDENCIAÇÃO E DIVULGAÇÃO DAS PRÁTICAS CONTÁBEIS APLICADAS AOS ATIVOS IMOBILIZADOS E INTANGÍVEIS, POR ENTIDADES LOCALIZADAS EM GOIÁS, SOB A ÓTICA DAS IFRS
}

\author{
DISCLOSURE AND GIVING INFORMATION OF ACCOUNTING PRINCIPLES APPLIED \\ TO INTANGIBLE AND FIXED ASSETS BY COMPANIES LOCATED IN GOIÂNIA, UNDER \\ THE PERSPECTIVE OF IFRS
}

\author{
Lúcio de Souza Machado \\ lucio@florestaaauditores.com.br \\ Universidade Federal de Goiás
}

\author{
Murilo Santos Floresta \\ murilo@florestaauditores.com.br \\ Universidade Federal de Goiás
}

Michele Rílany Rodrigues Machado
michelerilany@gmail.com
Universidade Federal de Goiás

\section{RESUMO}

Em face da edição das Leis 11.638/07 e 11.941/09, várias mudanças ocorreram no cenário contábil, em face das alterações promovidas na legislação societária brasileira, que culminou com a convergência das normas brasileiras ao padrão internacional (IFRS). A presente pesquisa teve como objetivo verificar o grau de atendimento das novas práticas contábeis aplicáveis aos ativos imobilizados e intangíveis, ao incluir o arrendamento mercantil financeiro (leasing) e ao teste de recuperabilidade, relativamente aos aspectos de divulgação e evidenciação. Por meio de uma pesquisa descritiva e de análise documental, foram analisadas as demonstrações contábeis de 35 entidades que divulgaram seus demonstrativos de 2010, no período de janeiro a novembro de 2011 em jornais de grande circulação na cidade de Goiânia-GO. A pesquisa apontou que, das 35 entidades analisadas, 18 (51,42\%) publicaram seus demonstrativos de forma inadequada. As análises efetuadas no imobilizado apontaram que poucas entidades atenderam aos quesitos apresentados e que as companhias de capital fechado se destacaram no cumprimento dos mesmos. Quanto ao ativo intangível e ao teste de recuperabilidade, os índices de atendimento foram menores do que aqueles do imobilizado. Além desse fato, o resultado que mais surpreende, revela que das 18 entidades excluídas da análise $7(38,89 \%)$ possuem seus demonstrativos auditados.

Palavras-chave: Convergência contábil, Divulgação, Imobilizado, Intangível.

\section{ABSTRACT}

Due to the enactment of Laws 11.638/07 and 11.941/09 several changes have occurred in the accounting scenario after the changes introduced in the Brazilian corporate legislation, culminating in the convergence of Brazilian standards to international standards (IFRS). This study is aimed to determine the degree of compliance with new accounting rules for fixed assets and intangible assets, including finance lease (leasing) and the impairment test, concerning aspects of disclosure. Through a descriptive and documentary analysis, we analyzed the financial statements of 35 companies that reported their financial statements in 2010, for the period January-November 2011 in newspapers of general circulation in Goiania-GO. The survey showed that 18 of the 35 companies analyzed (51.42\%) published their statements inaccurately. The analysis in fixed assets showed that few companies responded to the questions 
presented and privately held companies stood out in compliance. As for the intangible asset and the impairment test the attendance rates were lower than those of fixed assets. Moreover, the result is most surprising, it reveals that 18 of the companies excluded from the analysis 7 (38.89\%) have their statements audited.

Key words: Accounting convergence, Disclosure, Assets, Intangible.

Artigo recebido em: 25.11.2013; Aceito em: 15.02.2014

\section{Contextualização}

As grandes mudanças ocorridas no cenário contábil brasileiro em face da convergência das Normas Brasileiras de Contabilidade (NBCs) com aquelas editadas pelo IASB (InternationalAccounting Standards Boards), as conhecidas Normas Contábeis Internacionais ditas IFRS (International Financial Reporting Standard), iniciaram-se a partir da alteração da Lei n. ${ }^{\circ}$ 6.404/76 pela Lei ${ }^{\circ}$ 11.638/07 e, também, pela edição da Lei n. ${ }^{\circ}$ 11.941/09.

Os referidos dispositivos legais implementaram significativas mudanças nas práticas contábeis até então vigentes, especialmente, pelo grau de subjetividade decorrente dos métodos de reconhecimento e evidenciação atribuídos a alguns ativos e passivos, bem como, pelo impacto que tais mudanças geraram no resultado de algumas companhias.

A globalização dos negócios e a crescente evolução do mercado de capitais brasileiro, inevitavelmente, geraram a necessidade de se produzir e divulgar informações contábeis padronizadas, ou seja, de acordo o padrão IFRS. Logo, o processo de convergência e adequação às práticas contábeis internacionais pelas empresas brasileiras foi uma questão de tempo.

Durante muitos anos, a legislação fiscal interferiu no âmbito contábil determinando formas de contabilização, classificação e evidenciação de fatos contábeis, como exemplo, cita-se a determinação da vida útil dos bens e das taxas de depreciação aplicáveis aos ativos fixos. Em contrapartida, o novo padrão contábil brasileiro dá maior autonomia às práticas contábeis, uma vez que a Lei 11.638/07 incluiu ao artigo 177 da Lei 6.404/76, o seu $\S 5^{\circ}$, o qual dispõe que:

As normas expedidas pela Comissão de Valores Mobiliários a que se refere o $\S 3$ o deste artigo deverão ser elaboradas em consonância com os padrões internacionais de contabilidade adotados nos principais mercados de valores mobiliários.

O referido parágrafo eliminou a possibilidade de elaboração e divulgação de demonstrativos contábeis com parâmetros diferentes daqueles previstos nas normas contábeis, inclusive com critérios fiscais.

Além desse fato, entre os órgãos participantes do Comitê de Pronunciamentos Contábeis, temse como convidada a Receita Federal do Brasil, deste modo, influências fiscais na legislação contábil puderam ser adequadas, como exemplo, cita-se a implementação do Regime Tributário de Transição (RTT); o qual impede que as modificações ocorridas em detrimento do processo de convergência culminem em aumento ou redução da carga tributária.

Em pesquisas acadêmicas já realizadas no âmbito da convergência e harmonização das normas contábeis, já são constatados impactos e variações nos resultados de companhias abertas decorrentes da aplicação das novas normas; inclusive, na fase de transição para o IFRS, ocorrida nos anos de 2007e 2008 (SANTOS, 2010).

O que se tem observado, na prática, é que, de fato, o processo de convergência é extremamente complexo, o que vem sendo constatado, inclusive, em países que já adotaram o padrão IFRS. Yokoi (2008, p. 34-38), aponta que uma das preocupações em padronizar as normas contábeis 
ao padrão internacional é, justamente, o processo de convergência; uma vez que enquanto o mesmo não se completa há evidentes riscos de se vivenciar uma série de dialetos formados a partir de processos individuais de adaptação.

A International Organization of Securities Commissions (IOSCO), ou Organização Internacional das Comissões de Valores (OICV, sigla em português), em meados de 2008, solicitou junto às companhias dos mais diversos países que informassem o grau de utilização do padrão IFRS, com vistas a verificar se o mesmo estava sendo adotado integralmente pelas companhias. O receio da IOSCO era de que a informação e exigência de adoção do IFRS confundissem os investidores, de modo que supusessem que todos os relatórios financeiros de empresas são comparáveis, sendo que na prática, essa não era a realidade.

Desta forma, o problema orientador à realização da presente pesquisa consiste em: as entidades goianas, selecionadas por meio de acesso às publicações periódicas em jornais de grande circulação na cidade de Goiânia-GO, deram adequada publicidade às suas demonstrações contábeis do ano de 2010 publicadas no período de janeiro a novembro de 2011, ao considerar o novo padrão contábil nos quesitos de avaliação e divulgação? Tendo em vista a grande quantidade de normas aplicáveis, optou-se por avaliar aquelas relativas aos ativos fixos e intangíveis, de modo a verificar se o que foi publicado atende às exigências inerentes à avaliação e divulgação de informações contábil-financeiras.

Esta pesquisa tem como objetivo verificar o grau de atendimento das novas práticas contábeis aplicáveis aos ativos imobilizados e intangíveis (Resolução CFC No 1.177/2009 - Ativo Imobilizado; Resolução CFC No 1.263/2009 - Interpretação sobre a Aplicação Inicial ao Ativo Imobilizado e à Propriedade para Investimento; Resolução CFC No 1.292/2010 - Redução ao Valor Recuperável de Ativos; Resolução CFC No 1.303/2010 - Ativo Intangível; Resolução CFC 1.304/2010 - Operações de Arrendamento Mercantil), pelas 35 entidades objeto da análise.

Em face dos vários impactos gerados em decorrência de todo o processo de convergência às normas internacionais de contabilidade, sobretudo pela edição da Lei 11.638/07 que marca esse grande processo de mudança no cenário contábil brasileiro, entende-se que o tema abordado é imprescindível à reflexão dos profissionais da Contabilidade quanto à adequação das informações econômico-financeiras das entidades às IFRS, bem como da correta divulgação e evidenciação das referidas informações.

Além desse fato, o estudo se justifica em face da necessidade de averiguação quanto aos níveis de adequação às IFRS pelos profissionais contábeis, como, também, pelos administradores responsáveis pelas informações.

\section{Referencial Teórico}

\subsection{Alterações na legislação societária}

No Brasil, o processo de convergência das normas contábeis se tornou evidente com a edição da lei 11.638/07, publicada em 28/12/2007; uma vez que a mesma efetuou alterações no capítulo contábil da Lei das Sociedades por Ações (Lei 6.404/76), que inclui, entre outros avanços, a permissão para a convergência das normas contábeis, vigentes à época, às normas internacionais (CPC, 2008).

Neste cenário, surgiu o Comitê de Pronunciamentos Contábeis - CPC, que foi criado com o objetivo de viabilizar todo o processo de convergência aos padrões internacionais de contabilidade. 
Para tanto, algumas entidades foram convidadas a participar do processo, tendo em vista a vinculação direta das mesmas com a adoção de práticas contábeis nos vários segmentos existentes. Dentre elas, tem-se: ABRASCA - Associação Brasileira das Companhias Abertas, APIMEC - Associação Nacional dos Analistas e Profissionais de Investimento em Mercado de Capitais, BOVESPA - Bolsa do Brasil, CFC - Conselho Federal de Contabilidade, FIPECAFI - Fundação Instituto de Pesquisas Contábeis, Atuariais e Financeiras e IBRACON - Instituto dos Auditores Independentes do Brasil.

Ainda, participam como convidados observadores o BACEN - Banco Central do Brasil, a CVM - Comissão de Valores Imobiliários, a RFB - Receita Federal do Brasil e a SUSEP Superintendência de Seguros Privados. Também, de acordo com a natureza e do tema discutido, outras entidades e/ou especialistas são especialmente convidados (CPC, 2008).

O Brasil integra o grupo dos mais de 100 países, segundo dados do IASB de 2007, comprometidos com a adoção das IFRS. Tal fato se concretizou por iniciativa de órgãos reguladores como: Banco Central do Brasil (2006), Comissão de Valores Mobiliários (5/2005) e Superintendência de Seguros Privados (12/2007); os quais estabeleceram formalmente às entidades por eles reguladas a obrigatoriedade de elaborar e divulgar demonstrações contábeis consolidadas, a partir do exercício social findo em 31 de dezembro de 2010, no padrão IFRS (CPC, 2008).

Ressalta-se que grandes benefícios vieram em decorrência da modificação das práticas contábeis até então vigentes e, como exemplo, tem-se, a eliminação dos limites e critérios fiscais, especificamente relacionados à legislação do Imposto de Renda, que por um longo período limitaram a evolução dos Princípios Fundamentais de Contabilidade ou, ao menos, dificultaram sobremaneira a adoção prática de princípios contábeis adequados, uma vez que parte considerável das empresas baseava-se nos preceitos e critérios fiscais ao invés da boa prática contábil (IUDÍCIBUS; MARTINS; GELBCKE, 2010).

Em contrapartida, várias preocupações se externaram em função dos impactos inerentes às novas práticas como: alteração nos resultados e no patrimônio líquido das empresas, o aumento do grau de subjetividade das informações devido aos critérios de avaliação e evidenciação de alguns ativos e passivos.

\subsection{Evidenciação e divulgação nas novas práticas aplicadas aos ativos imobilizados}

Com a convergência das práticas contábeis em IFRS, determinou-se, por essência, a preponderância da "realidade" econômica espelhada em práticas contábeis que evidenciem com maior transparência a posição financeira dos ativos fixos. Nesta ótica, os ativos precisam ser evidenciados pelo custo de aquisição, menos a depreciação acumulada e menos as perdas não recuperáveis (Resolução CFC No 1.292/2010).

Em conformidade com o que prevê a Resolução CFC n ${ }^{\circ}$. 1.177/09, as demonstrações contábeis devem divulgar uma série de informações necessárias aos usuários, bem como refletir transparência no saldo registrado e nas movimentações efetuadas em cada grupo de contas. Como exemplo, cita-se alguns dos principais itens a serem divulgados: a) os critérios de mensuração utilizados para determinar o valor contábil bruto; b) os métodos de depreciação utilizados; c) as vidas úteis ou as taxas de depreciação utilizadas; d) o valor contábil bruto e a depreciação acumulada (mais as perdas por redução ao valor recuperável acumuladas) no início e no final do período; e e) a conciliação do valor contábil no início e no final do período demonstrando: i) adições; ii) ativos classificados para venda ou mantidos para tal fim; iii) outras alterações no grupo.

Além desse fato, as demonstrações também devem divulgar a existência de bens dados em garantia em operações de crédito porventura realizadas; ativos adquiridos por contratos de 
leasing (arrendamento mercantil); os custos de construção de imobilizado em andamento; entre outros.

Ressalta-se, que um fator de peso influenciou as práticas contábeis por longos anos, ou seja, as práticas fiscais determinadas pela Receita Federal do Brasil, especialmente, quanto à estimativa de vida útil dos ativos fixos e das taxas de depreciação aplicáveis aos mesmos. Tal influência pode ser observada nos anexos I e II, previstos nos incisos I e II, do artigo $1^{\circ}$, da Instrução Normativa SRF No 162, de 31 de dezembro de 1998; de modo que a referida instrução dispõe que as quotas de depreciação, classificadas como custo ou despesa, a serem registradas na escrituração da pessoa jurídica, serão determinadas com base nos prazos de vida útil e nas taxas de depreciação previstas nos referidos anexos.

Ao considerar essa influência fiscal nas práticas contábeis brasileiras, muitas empresas adotaram como taxas de depreciação aquelas determinadas pela legislação fiscal e, assim, em uma análise preliminar de um cenário "fiscal" tem-se que as referidas taxas foram determinadas em estudos passados acerca da vida útil estimada dos bens, de modo que tais valores, em muitas situações, podem ter razoável aproximação da realidade, em contrapartida, pode haver significativos desvios (Resolução CFC No 1.263/2009).

Nesta ótica, e ao considerar as novas práticas contábeis, tem-se que as empresas, quando da publicidade e divulgação das demonstrações financeiras, devem apresentar em notas explicativas todas as informações necessárias à correta divulgação e evidenciação das informações relativas ao imobilizado, conforme já mencionado.

Também, ressalta-se que as empresas deverão evidenciar quando foi feita a adoção inicial das NBCs TG 27, TG 37 e TG 43, de preferência em notas explicativas que trate acerca das práticas contábeis adotadas, bem como da opção ou não pelos ajustes relativos ao custo atribuído (deemed cost) a seus ativos imobilizados, indicando: a) a base de avaliação utilizada e a razão de sua escolha; e b) os efeitos sobre o balanço de abertura do exercício social em que se der essa aplicação inicial, discriminados por conta ou grupo de contas do ativo imobilizado conforme evidenciados no balanço patrimonial, bem como as parcelas alocadas ao passivo não circulante (tributos diferidos) e ao patrimônio líquido (Resolução CFC No 1.263/2009).

O custo atribuído é mais uma novidade trazida pela convergência das normas contábeis, a qual permite que as empresas possam evidenciar com mais fidedignidade o valor dos seus ativos fixos, conforme prevê a Resolução CFC ${ }^{\circ}$. 1.263/09. Nesta ótica, caso a entidade identifique bens de valores relevantes e que tenham provável geração de caixa futuro, mas, que encontramse registrados por valor substancialmente inferior, incentiva-se seja feita a atribuição de custos para que os mesmos reflitam seu valor justo dando maior qualidade às informações patrimoniais. Contudo, tal prática pode ser efetuada uma única vez e quando da adoção inicial das novas práticas contábeis.

\subsection{Adoção da essência econômica sobre a forma jurídica dos contratos de leasing financeiro}

$\mathrm{Na}$ modalidade de leasing financeiro há a particularidade de que os benefícios e os riscos inerentes ao bem, objeto do contrato, são transferidos ao arrendatário. Conforme item 4 da Resolução CFC Nº 1.304/2010, arrendamento mercantil financeiro é aquele em que há transferência substancial dos riscos e benefícios inerentes à propriedade de um ativo. $\mathrm{O}$ título de propriedade pode ou não vir a ser transferido (IUDÍCIBUS; MARTINS; GELBCKE, 2010). Anteriormente à edição da Lei 11.638/2007, qualquer modalidade de arrendamento mercantil (financeiro ou operacional), era classificada como despesa na arrendatária quando do vencimento das contraprestações mensais. Tal prática se mantinha em virtude de que entendiase que as referidas contraprestações consistiam em preço pago pelo aluguel do bem arrendado; logo, nenhum registro de ativo e passivo era efetuado sob o argumento de que a arrendatária 
não detinha o título de propriedade do bem arrendado (IUDÍCIBUS; MARTINS; GELBCKE, 2010).

Todavia, com as alterações promovidas pela Lei 11.638/2007, especialmente, no artigo 179 da Lei 6.404/1976, no seu item IV, tem-se que devem fazer parte do ativo imobilizado "os direitos que tenham por objeto bens corpóreos destinados à manutenção das atividades da companhia ou da empresa ou exercidos com essa finalidade, inclusive os decorrentes de operações que transfiram à companhia os benefícios, riscos e controle desses bens".

Desta forma, a alteração reforça a necessidade da primazia da essência sobre a forma e, além disso, permite uma avaliação mais adequada dos ativos imobilizados e dos passivos correlatos; uma vez que na prática anterior, de fato, havia subavaliação do ativo pelo não registro do bem, como também do passivo pelo não reconhecimento da dívida (financiamento em modalidade de leasing).

Ainda, ao se tratar de divulgação e evidenciação de tais informações nos demonstrativos contábeis, deve o arrendatário divulgar todos os aspectos anteriormente mencionados no tópico 2.2 e, também, a conciliação entre o total dos futuros pagamentos mínimos do arrendamento, ao final do período, e o seu valor presente segregados em: a) até um ano; b) mais de um ano e até cinco anos; e c) mais de cinco anos; os pagamentos contingentes reconhecidos como despesa durante o período; descrição geral dos acordos de arrendamento como a base em que é determinado o pagamento contingente; existência e condições para opção de renovação ou de compra, bem como cláusulas de reajustamento; restrições impostas por acordo, tais como as relativas a dividendos e juros sobre o capital próprio, dívida adicional e posterior arrendamento mercantil; entre outras.

Para os demonstrativos dos arrendadores, além de algumas divulgações comuns aos arrendatários, deverão ainda apresentar a receita financeira não realizada, os valores residuais não garantidos que resultem em benefício do arrendador, as provisões para pagamentos mínimos incobráveis do arrendamento a receber, os pagamentos contingentes reconhecidos como receita durante o período, a descrição geral dos acordos materiais de arrendamento do arrendador e, finalmente, o investimento bruto menos a receita não realizada em novos negócios realizados durante o período, após a dedução dos valores relevantes dos arrendamentos mercantis cancelados.

\subsection{Avaliação e divulgação dos ativos intangíveis}

A Resolução CFC No. 1.303/2010 define ativo intangível como "um ativo não monetário identificável sem substância física." Tais ativos, também, são caracterizados por gerarem benefícios futuros e serem passíveis de controle pelas empresas e, também, são representados, principalmente, por marcas, patentes, softwares e goodwill. Os intangíveis podem ter vida útil definida ou indefinida, de modo que aqueles com vida útil definida são amortizados na medida em que há a redução da referida vida útil (REINA et al., 2009).

Para fins de atendimento às novas práticas contábeis, os ativos intangíveis devem ser divulgados e apresentados nas demonstrações contábeis de modo a distinguir cada classe de intangíveis, ou seja, ativos intangíveis gerados internamente e outros ativos intangíveis.

Além desse fato, dentre as principais características que devem ser observadas e divulgadas nas demonstrações contábeis, tem-se: a) apresentar se o ativo possui vida útil indefinida ou definida e, se definida, os prazos de vida útil ou as taxas de amortização utilizadas; b) os métodos de amortização utilizados para ativos intangíveis com vida útil definida; c) o valor contábil bruto e eventual amortização acumulada (mais as perdas acumuladas no valor recuperável) no início e no final do período; d) a conciliação do valor contábil no início e no final do período, demonstrando: 1) adições; 2) ativos classificados como mantidos para venda ou incluídos em 
grupo de ativos classificados como mantidos para venda; 3) aumentos ou reduções durante o período; 4) provisões para perdas de ativos, reconhecidas no resultado do período; 5) reversão de perda por desvalorização de ativos, apropriada ao resultado do período; 6) entre outras.

Nesta ótica, tem-se que a divulgação e evidenciação de informações nos demonstrativos financeiros são: completas, quando se maximiza a publicidade das informações aos usuários, uma vez que tais informações são relevantes; justas, na medida em que há igualdade a todos os usuários do ponto de vista da evidenciação; e adequadas, quando apenas são divulgadas informações relevantes (YAMAMOTO; SALOTTI, 2006).

Em contrapartida à norma apresentada e aos requisitos básicos de qualidade na divulgação e evidenciação de informações contábeis, Antunes, Leite e Guerra (2007), ao avaliar e percepção de 18 analistas de investimento quanto ao procedimento normativo de divulgação das informações relativas ao intangível, apuraram que as mesmas são insuficientes para uma avaliação apropriada das empresas, uma vez que para se completar tal análise faz-se necessária coleta indireta de informações.

Sob a ótica do disclosure, Antunes, Silva e Saiki (2009), identificaram em estudo que mais de $50 \%$ das empresas analisadas divulgaram o tempo de vida útil dos ativos intangíveis, e somente $23 \%$ deixaram de evidenciar as taxas utilizadas par amortização.

\subsection{Teste de recuperabilidade aplicado aos ativos fixos}

O pronunciamento contábil de que trata do teste de Impairment o CPC 01, o qual foi convertido pelo Conselho Federal de Contabilidade na Resolução CFC Nº. 1.292/2010. Tais normativos puderam ser viabilizados em face das alterações promovidas na legislação societária, sobretudo, com a inclusão, do $\S 3^{\circ}$, no artigo 183 , da Lei 6.404/1796, feita pelo artigo $1^{\circ}$ da Lei 11.638/07. Esta inclusão na legislação determinou às companhias, que os elementos pertencentes ao imobilizado e ao intangível deverão ser, periodicamente, revisados de sorte a analisar a recuperação dos valores registrados, a fim de que sejam: a) registradas as perdas de valor do capital aplicado, quando houver decisão de interromper os empreendimentos ou atividades a que se destinavam, ou quando comprovado que os fluxos de caixa futuros não serão suficientes para recuperação do valor registrado; ou b) revisados e adequados os critérios utilizados para a determinação da vida útil econômica estimada, bem como aqueles empregados no cálculo da depreciação, exaustão e amortização, uma vez que critérios eminentemente fiscais, comumente utilizados até 2007, devem ser revistos e sobrepostos à boa prática contábil (IFRS).

A referida inclusão na legislação faz com que as empresas tenham de efetuar, periodicamente (diga-se, pelo menos uma vez ao ano), avaliação de tais ativos com o objetivo de verificar se seu valor contábil está subavaliado ou superavaliado.

O objetivo básico do referido teste é assegurar que o valor contábil líquido de um ativo não esteja registrado por um valor maior do que o seu valor recuperável (ALMEIDA, 2010). Considerando a previsão legal para o teste de recuperabilidade, bem como os porquês de se efetuar, conclui-se que o referido teste é conveniente e, de fato, contribui para uma avaliação mais qualitativa das informações, uma vez que análises efetuadas sobre as informações de tais ativos tendem a gerar diagnóstico mais preciso do analista (STICKNEY e WEIL, 2008).

Quanto aos aspectos de divulgação e evidenciação das informações relativas ao teste de recuperabilidade, entidade deve publicar, para cada classe de ativos, inclusive os reavaliados, o montante das perdas por desvalorização reconhecida no resultado, bem como das reversões de perdas por desvalorização e, além disso, indicar a linha da demonstração do resultado a qual foram inseridas as referidas perdas.

Um dos aspectos importantes na divulgação das informações inerentes ao teste de recuperabilidade é a evidenciação quanto à natureza do valor recuperável do ativo (unidade 
geradora de caixa), ou seja, se o valor adotado foi seu valor justo líquido de despesa de venda, ou seu valor em uso. Nesta ótica, sendo o valor justo deve-se evidenciar a base considerada para se determinar tal valor, e se for o valor em uso deve-se apresentar a taxa de desconto utilizada na estimativa corrente e na estimativa anterior (se houver).

Finalmente, deve-se, também, apresentar em notas explicativas as principais classes dos ativos afetados por perdas por desvalorização, bem como das reversões e, além disso, os principais eventos e circunstâncias que levaram ao reconhecimento das referidas perdas e reversões.

\section{Metodologia da Pesquisa}

A pesquisa caracteriza-se como descritiva, bibliográfica e documental, de modo que para se atender aos objetivos propostos adota-se uma abordagem qualitativa dos demonstrativos contábeis de 35 entidades, relativos ao ano de 2010 e publicados em 2011 por meio de jornais de grande circulação na cidade de Goiânia-GO, no período de janeiro a novembro de 2011.

Para análise das informações divulgadas e evidenciadas nos demonstrativos contábeis segregou-se os parâmetros de análise por grupo de informações, de modo a dar independência às análises. Os grupos subdividem-se em ativo imobilizado, arrendamento mercantil (leasing), ativo intangível e teste de recuperabilidade (impairment).

Assim sendo, por meio de uma análise qualitativa baseada nas normas contábeis de divulgação, específicas para cada classe de ativo objeto da pesquisa, foram determinados quatro quesitos para cada grupo, com o objetivo de identificá-los ou não dos demonstrativos analisados e, nesta ótica, para cada quesito atribui-se SIM ou NÃO quanto ao atendimento do mesmo, sendo que, ao final da análise, avalia-se o percentual de entidades que cumpriram e não cumpriram os aspectos normativos de divulgação das demonstrações contábeis.

Além desse fato, foram excluídas do universo da amostra as entidades que divulgaram seus demonstrativos de forma inadequada e sem as condições mínimas para análise (demonstrações contábeis apresentando notas explicativas com supressão exacerbada de informações passíveis de divulgação), ou aquelas em que as informações sob análise (imobilizado, arrendamento mercantil e intangível), não fizeram parte dos demonstrativos em face de as entidades não possuírem imobilizado ou intangível, bem como não possuírem ativos fixos adquiridos na modalidade de leasing.

\subsection{Quesitos para análise}

Os quesitos utilizados na análise de conteúdo das informações foram definidos em conformidade com a normativa contábil que dispõe sobre cada grupo de informações, quais sejam: ativo imobilizado, arrendamento mercantil (leasing), ativo intangível e teste de recuperabilidade (impairment). Abaixo, têm-se as informações por grupo, como seguem:

\begin{tabular}{|c|c|c|}
\hline $\mathrm{N}^{\circ}$ & Quesito & Fundamentação \\
\hline 1 & $\begin{array}{l}\text { Foi mencionada em notas explicativas a revisão das taxas de } \\
\text { depreciação ou revisão da vida útil dos bens. }\end{array}$ & $\begin{array}{l}\text { Resolução CFC } n^{\circ} .1 .177 / 09 \text {, item } 51 ; \\
\S 3^{\circ} \text {, inciso II, do artigo } 183 \text {, da Lei } \\
6.404 / 76 \text {; Resolução CFC } n^{\circ} \text {. } \\
1.263 / 09 \text {, itens } 1,3 \text { e } 6 .\end{array}$ \\
\hline
\end{tabular}




\begin{tabular}{|c|c|c|}
\hline 2 & $\begin{array}{l}\text { Foi mencionado em notas explicativas a determinação de valor } \\
\text { residual para os bens os quais espera-se que, ao final de sua } \\
\text { vida útil, alienação, transferência, etc., haja expectativa de } \\
\text { recuperação. }\end{array}$ & $\begin{array}{l}\text { Resolução CFC n }{ }^{\circ} .1 .263 / 09 \text {, itens } 1 \text {, } \\
7,18 \text { e } 23 .\end{array}$ \\
\hline 3 & $\begin{array}{l}\text { Foi evidenciada a opção pela atribuição de custos para os bens } \\
\text { relevantes e com expectativa de geração de caixa futuro, mas, } \\
\text { que encontram-se registrados por valor inferior ou superior ao } \\
\text { seu valor justo; ou essa opção não foi adotada pela sociedade. }\end{array}$ & $\begin{array}{l}\text { Resolução CFC nº. 1.263/09, itens } 23 \\
\text { e } 24 .\end{array}$ \\
\hline 4 & $\begin{array}{l}\text { Foi evidenciada em notas explicativas a conciliação do valor } \\
\text { contábil no início e final do período demonstrando adições, } \\
\text { ativos classificados como mantidos para venda, aquisições por } \\
\text { combinação de negócios, aumento ou redução por impairment, } \\
\text { reversão de perdas, depreciações, outras alterações. }\end{array}$ & $\begin{array}{l}\text { Resolução CFC nº 1.177/09 item73, } \\
\text { alínea "e". }\end{array}$ \\
\hline
\end{tabular}

Fonte: Elaborado com base em: Resolução CFC nº. 1.177/09 (CPC 27) e Resolução CFC nº. 1.263/09 (ICPC 10).

Quadro 2: Detalhamento dos quesitos que embasaram a análise de conteúdo do arrendamento mercantil financeiro

\begin{tabular}{|c|c|c|}
\hline $\mathbf{N}^{\circ}$ & Descrição & Fundamentação \\
\hline 1 & $\begin{array}{l}\text { Foi feita indicação em notas explicativas da adoção das novas } \\
\text { práticas contábeis aplicáveis aos bens adquiridos via } \\
\text { contratos de leasing (financeiro) }\end{array}$ & Artigo 177 da Lei 6.404/76. \\
\hline 2 & $\begin{array}{l}\text { Os bens adquiridos via contratos de leasing foram registrados } \\
\text { no ativo imobilizado, com a contrapartida do lançamento } \\
\text { feita no passivo. }\end{array}$ & $\begin{array}{l}\text { Inciso IV, do artigo } 179 \text {, da Lei } \\
6.404 / 76 \text {; Resolução CFC no. } 1.304 / 10 \text {, } \\
\text { do item } 20 \text { ao } 23 \text {. }\end{array}$ \\
\hline 3 & $\begin{array}{l}\text { Foi evidenciada em notas explicativas a realização de teste } \\
\text { de recuperabilidade para os ativos arrendados integrantes do } \\
\text { imobilizado e do intangível. }\end{array}$ & Resolução CFC no. 1.304/10, item 32. \\
\hline 4 & $\begin{array}{l}\text { Foi feita conciliação entre o total dos futuros pagamentos } \\
\text { mínimos do arrendamento, até o final do período, com o seu } \\
\text { valor presente segregado em a) até um ano; b) mais de um } \\
\text { ano e até cinco anos; e c) mais de cinco anos. }\end{array}$ & $\begin{array}{l}\text { Resolução CFC n'. 1.304/10, item 31, } \\
\text { alínea "b". }\end{array}$ \\
\hline
\end{tabular}

Fonte: Elaborado com base em: Resolução CFC nº. 1.256/09 (ICPC 03) e Resolução CFC nº. 1.304/10 (CPC 06).

Quadro 3: Detalhamento dos quesitos que embasaram a análise de conteúdo do ativo intangível

\begin{tabular}{|c|l|l|}
\hline $\mathbf{N}^{\mathbf{0}}$ & \multicolumn{1}{|c|}{ Descrição } & \multicolumn{1}{|c|}{ Fundamentação } \\
\hline 1 & $\begin{array}{l}\text { Foi evidenciado em notas explicativas da adoção das novas } \\
\text { práticas contábeis aplicáveis aos ativos intangíveis. }\end{array}$ & Artigo 177 da Lei 6.404/76. \\
\hline 2 & $\begin{array}{l}\text { Foi feita indicação em notas explicativas dos ativos } \\
\text { intangíveis com vida útil definida e daqueles com vida útil } \\
\text { indefinida. }\end{array}$ & $\begin{array}{l}\text { Resolução CFC no. 1.303/10, item 118, } \\
\text { alínea "a'. }\end{array}$ \\
\hline 3 & $\begin{array}{l}\text { Indicação das taxas de amortização conforme vida útil, para } \\
\text { os intangíveis classificados como de vida definida. }\end{array}$ & $\begin{array}{l}\text { Resolução CFC no. 1.303/10, item 118, } \\
\text { alínea "a'. }\end{array}$ \\
\hline 4 & $\begin{array}{l}\text { Indicação dos métodos de amortização aplicados aos } \\
\text { intangíveis de vida útil definida. Tais métodos incluem o } \\
\text { método linear, também conhecido como método de linha } \\
\text { reta, o método dos saldos decrescentes e o método de } \\
\text { unidades produzidas. }\end{array}$ & $\begin{array}{l}\text { Resolução CFC no. 1.303/10, item 98 e, } \\
\text { item 118, alínea "b". }\end{array}$ \\
\hline
\end{tabular}

Fonte: Elaborado com base em: Resolução CFC nº. 1.303/10. 
Quadro 4: Detalhamento dos quesitos que embasaram a análise de conteúdo do teste de recuperabilidade

\begin{tabular}{|c|c|c|}
\hline $\mathbf{N}^{\circ}$ & Descrição & Fundamentação \\
\hline 1 & $\begin{array}{l}\text { Foi feita indicação nas notas explicativas de que foi feito } \\
\text { teste de recuperabilidade para os ativos imobilizados e } \\
\text { intangíveis registrados, de modo a evidenciar a existência } \\
\text { ou não de indicadores de perda por desvalorização. }\end{array}$ & $\begin{array}{l}\S 3^{\circ} \text {, do artigo } 183 \text { e } \S 5^{\circ} \text {, inciso IV, } \\
\text { alínea "a", do artigo } 176 \text {, da Lei } \\
6.404 / 76 ; \text { Resolução } \quad \text { CFC } \\
\text { 1.292/10, itens } 9 \text { e } 10 .\end{array}$ \\
\hline 2 & $\begin{array}{l}\text { Foram divulgados os indicadores de perda por } \\
\text { desvalorização identificados no teste de recuperabilidade, a } \\
\text { entidade evidenciou o montante das perdas, por grupo de } \\
\text { ativos, inclusive das reversões de perda ocorridas; ou a não } \\
\text { existência de indicadores de perda, por grupo. }\end{array}$ & $\begin{array}{l}\text { Inciso I do } \S 3^{\circ} \text {, do artigo } 183 \text {, da Lei } \\
6.404 / 76 \text {; Resolução CFC } n^{\circ} .1 .292 / 10 \text {, } \\
\text { item } 126 \text { e alíneas. }\end{array}$ \\
\hline 3 & $\begin{array}{l}\text { Houve indicação das estimativas utilizadas para mensurar o } \\
\text { valor recuperável das unidades geradoras de caixa } \\
\text { (imobilizado) quando o ágio por expectativa de } \\
\text { rentabilidade futura ou o ativo intangível de vida útil } \\
\text { indefinida estiver incluído no valor contábil da unidade. }\end{array}$ & $\begin{array}{l}\text { Resolução CFC no }{ }^{\circ} .1 .292 / 10 \text {, itens } 132 \\
\text { e } 134 .\end{array}$ \\
\hline 4 & $\begin{array}{l}\text { Foi feita indicação nas notas explicativas das principais } \\
\text { classes de ativos afetadas por perdas, bem como as } \\
\text { circunstâncias e eventos que levaram ao referido } \\
\text { reconhecimento. }\end{array}$ & $\begin{array}{l}\text { Resolução CFC n }{ }^{\circ} .1 .292 / 10, \text { item } 131 \\
\text { e alíneas. }\end{array}$ \\
\hline
\end{tabular}

Fonte: Elaborado com base em: Resolução CFC Nº. 1.292/10.

\section{Resultado da Análise}

As entidades objeto da análise representam 35, de modo que 8,57\% são associações, 5,71\% cooperativas, $2,86 \%$ empresas públicas, $2,86 \%$ fundações, $60 \%$ sociedades anônimas de capital fechado, $5,71 \%$ sociedade de economia mista de capital aberto e $14,29 \%$ sociedade de economia mista, de capital fechado.

De acordo com as análises efetuadas nos 35 demonstrativos contábeis, sob a ótica dos quesitos levantados para verificação quanto à adequação da divulgação, 51,42\% das entidades objeto da pesquisa (18) foram excluídas da análise por terem divulgado suas demonstrações contábeis de forma inadequada e sem as condições mínimas de análise.

Desta forma, tendo em vista a exclusão de 18 entidades fez-se necessário o estabelecimento de um novo número para verificação, de sorte que o total objeto da análise $(n=35)$ menos o total excluído $\left(\mathrm{n}_{1}=18\right)$ é igual a $\left(\mathrm{n}_{2}=17\right)$. Em face do contexto inicial apresentado, constata-se que mais da metade das entidades objeto da pesquisa, divulgaram seus demonstrativos de forma inadequada e fora dos padrões contábeis exigidos.

Além desse fato, ressalta-se que das 35 entidades objeto da pesquisa $62,86 \%$, que correspondem a 22 entidades, foram auditadas por auditores independentes e, das excluídas (18) 38,89\% também submeteram seus demonstrativos à auditoria independente.

\subsection{Avaliação e evidenciação do ativo imobilizado}

De acordo com as análises efetuadas quanto ao ativo imobilizado, das 17 entidades que constituem o $\mathrm{n}_{2}$, (1) uma foi excluída por não apresentar grupo de imobilizado na estrutura do 
balanço patrimonial, logo, novo $\mathrm{n}$ foi determinado $\left(\mathrm{n}_{3}=16\right)$. Das 16 analisadas 37,50\% atenderam ao quesito $\mathrm{n}^{\circ} 1 ; 18,75 \%$ atenderam ao quesito $\mathrm{n}^{\circ} 2 ; 37,50 \%$ atenderam ao quesito $\mathrm{n}^{\circ}$ 3 ; e $56,25 \%$ atenderam ao quesito de $n^{\circ} 4$.

Abaixo, segue comparativo de atendimento aos quesitos, por natureza societária:

Tabela 1 - Dados de análise do ativo imobilizado

\begin{tabular}{l|r|r|r|r}
\hline DESCRIÇÃO & QUESITO 1 & QUESITO 2 & QUESITO 3 & QUESITO 4 \\
\hline Associação & $0,00 \%$ & $0,00 \%$ & $0,00 \%$ & $0,00 \%$ \\
Cooperativa & $0,00 \%$ & $0,00 \%$ & $0,00 \%$ & $0,00 \%$ \\
Empresa pública & $0,00 \%$ & $0,00 \%$ & $0,00 \%$ & $0,00 \%$ \\
Fundação & $0,00 \%$ & $0,00 \%$ & $0,00 \%$ & $0,00 \%$ \\
Sociedade anônima - capital fechado & $31,25 \%$ & $18,75 \%$ & $31,25 \%$ & $50,00 \%$ \\
Sociedade de economia mista de capital aberto & $0,00 \%$ & $0,00 \%$ & $0,00 \%$ & $6,25 \%$ \\
Sociedade de economia mista de capital fechado & $6,25 \%$ & $0,00 \%$ & $6,25 \%$ & $0,00 \%$ \\
\hline TOTAL & $\mathbf{3 7 , 5 0 \%}$ & $\mathbf{1 8 , 7 5 \%}$ & $\mathbf{3 7 , 5 0 \%}$ & $\mathbf{5 6 , 2 5 \%}$ \\
\hline
\end{tabular}

Fonte: Elaboração própria.

Em análise do quadro acima, conclui-se que as empresas constituídas sob a forma de sociedades anônimas de capital fechado atenderam, pelo menos em parte, os quesitos de divulgação e evidenciação do imobilizado, ao contrário das demais modalidades societárias.

\subsection{Avaliação e evidenciação do leasing financeiro}

$\mathrm{Na}$ análise inerente ao leasing financeiro (arrendamento mercantil financeiro), 16 das 17 entidades objeto da análise (ou seja, 94,12\%) também foram excluídas, pois, não apresentaram qualquer evidência da existência de bens adquiridos via arrendamento mercantil, o que também, constitui fator que obsta a análise dos demonstrativos.

Por conseguinte, apenas 1 empresa (5,88\%), a qual, é constituída sob a forma de sociedade anônima de capital fechado, apresentou arrendamento mercantil financeiro em seus demonstrativos, $\operatorname{logo}, \mathrm{n}=17$ passou a ser $\mathrm{n}_{1}=1(100 \%)$ e, da análise efetuada, os quesitos 1 e 2 foram atendidos, ao contrário dos quesitos 3 e 4 , que não foram evidenciados nas demonstrações, conforme quadro abaixo:

Tabela 2 - Dados de análise do leasing financeiro

\begin{tabular}{l|r|r|r|r}
\hline DESCRIÇÃO & QUESITO 1 & QUESITO 2 & QUESITO 3 & QUESITO 4 \\
\hline Associação & $0,00 \%$ & $0,00 \%$ & $0,00 \%$ & $0,00 \%$ \\
Cooperativa & $0,00 \%$ & $0,00 \%$ & $0,00 \%$ & $0,00 \%$ \\
Empresa pública & $0,00 \%$ & $0,00 \%$ & $0,00 \%$ & $0,00 \%$ \\
Fundação & $0,00 \%$ & $0,00 \%$ & $0,00 \%$ & $0,00 \%$ \\
Sociedade anônima - capital fechado (1) & $100,00 \%$ & $100,00 \%$ & $0,00 \%$ & $0,00 \%$ \\
Sociedade de economia mista de capital aberto & $0,00 \%$ & $0,00 \%$ & $0,00 \%$ & $0,00 \%$ \\
Sociedade de economia mista de capital fechado & $0,00 \%$ & $0,00 \%$ & $0,00 \%$ & $0,00 \%$ \\
\hline TOTAL & $\mathbf{1 0 0 , 0 0 \%}$ & $\mathbf{1 0 0 , 0 0 \%}$ & $\mathbf{0 , 0 0 \%}$ & $\mathbf{0 , 0 0 \%}$ \\
\hline
\end{tabular}


Fonte: Elaboração própria.

Assim sendo, conclui-se que as entidades poderiam ter informado que não atenderam o que dispõe a Resolução $\mathrm{CFC} \mathrm{n}^{\circ}$. 1.304/10 (Arrendamento Mercantil); tendo em vista a não existência de ativos adquiridos por meio de arrendamento. Logo, entende-se que a qualidade da informação poderia ser melhor, uma vez que tratando-se de mudança recente na legislação societária essa informação agregaria maior transparência aos demonstrativos.

\subsection{Avaliação e evidência do ativo intangível}

No tocante às análises do ativo intangível 2 entidades foram excluídas da análise em face de não apresentar ativo intangível em seus demonstrativos, logo, o $\mathrm{n}_{2}$ que antes era igual a 17 passa a ser $n_{3}=15$.

Das 15 entidades, 66,67\% atenderam ao quesito $n^{\circ} 1 ; 6,67 \%$ atenderam ao quesito $n^{\circ} 2 ; 26,67 \%$ atenderam ao quesito $\mathrm{n}^{\circ} 3$; e 13,33\% atenderam ao quesito $\mathrm{n}^{\circ} 4$. Abaixo, segue quadro com o desempenho, por tipo societário, no atendimento aos quesitos, como segue:

Tabela 3 - Dados de análise do ativo intangível

\begin{tabular}{l|r|r|r|r}
\hline DESCRIÇÃO & QUESITO 1 & QUESITO 2 & QUESITO 3 & QUESITO 4 \\
\hline Associação & $0,00 \%$ & $0,00 \%$ & $0,00 \%$ & $0,00 \%$ \\
Cooperativa & $0,00 \%$ & $0,00 \%$ & $6,67 \%$ & $6,67 \%$ \\
Empresa pública & $0,00 \%$ & $0,00 \%$ & $0,00 \%$ & $0,00 \%$ \\
Fundação & $0,00 \%$ & $0,00 \%$ & $0,00 \%$ & $0,00 \%$ \\
Sociedade anônima - capital fechado & $53,33 \%$ & $6,67 \%$ & $20,00 \%$ & $6,67 \%$ \\
Sociedade de economia mista de capital aberto & $6,67 \%$ & $0,00 \%$ & $0,00 \%$ & $0,00 \%$ \\
Sociedade de economia mista de capital fechado & $6,67 \%$ & $0,00 \%$ & $0,00 \%$ & $0,00 \%$ \\
\hline TOTAL & $\mathbf{6 6 , 6 7 \%}$ & $\mathbf{6 , 6 7 \%}$ & $\mathbf{2 6 , 6 7 \%}$ & $\mathbf{1 3 , 3 3 \%}$ \\
\hline
\end{tabular}

Fonte: Elaboração própria.

Conforme quadro demonstrativo acima tem-se que as companhias de capital fechado apresentam índices de atendimento dos quesitos superior aos demais tipos societários e, nesta ótica, conclui-se que poucas entidades estão atentando para a necessidade de cumprimento das normas contábeis, sobretudo, com relação aos aspectos de divulgação exigidos pelos normativos e necessários à maior transparência e qualidade das informações.

\subsection{Avaliação e evidência do teste de recuperabilidade}

Relativamente ao teste de recuperabilidade constatou-se que $64,71 \%$ das entidades atenderam ao quesito $\mathrm{n}^{\mathrm{o}} 1 ; 29,41 \%$ atenderam ao quesito $\mathrm{n}^{\mathrm{o}} 2 ; 11,76 \%$ atenderam ao quesito $\mathrm{n}^{\mathrm{o}} 3$; e $0,00 \%$ atenderam o quesito $n^{\circ} 4$. Abaixo, segue quadro demonstrativo:

Tabela 4 - Dados de análise do teste de recuperabilidade

\begin{tabular}{l|r|r|r|r}
\hline DESCRIÇÃO & QUESITO 1 & QUESITO 2 & QUESITO 3 & QUESITO 4 \\
\hline Associação & $0,00 \%$ & $0,00 \%$ & $0,00 \%$ & $0,00 \%$
\end{tabular}




\begin{tabular}{l|r|r|r|r} 
Cooperativa & $0,00 \%$ & $0,00 \%$ & $0,00 \%$ & $0,00 \%$ \\
Empresa pública & $0,00 \%$ & $0,00 \%$ & $0,00 \%$ & $0,00 \%$ \\
Fundação & $0,00 \%$ & $0,00 \%$ & $0,00 \%$ & $0,00 \%$ \\
Sociedade anônima - capital fechado & $52,94 \%$ & $23,53 \%$ & $5,88 \%$ & $0,00 \%$ \\
Sociedade de economia mista de capital aberto & $5,88 \%$ & $5,88 \%$ & $0,00 \%$ & $0,00 \%$ \\
Sociedade de economia mista de capital fechado & $5,88 \%$ & $0,00 \%$ & $5,88 \%$ & $0,00 \%$ \\
\hline TOTAL & $\mathbf{6 4 , 7 1 \%}$ & $\mathbf{2 9 , 4 1 \%}$ & $\mathbf{1 1 , 7 6 \%}$ & $\mathbf{0 , 0 0 \%}$ \\
\hline
\end{tabular}

Fonte: Elaboração própria.

Com base nas informações do quadro acima, nota-se que os aspectos de divulgação intrínsecos ao teste de recuperabilidade, também não estão sendo evidenciados adequadamente nos demonstrativos contábeis, e o que nos chama mais a atenção é que mais de $50 \%$ das demonstrações analisadas são auditadas por auditores independentes, que, em tese, deveriam revisar as demonstrações e orientar os responsáveis quanto aos aspectos necessários a uma adequada divulgação.

Ainda, tem-se que apesar do baixo atendimento aos quesitos estabelecidos as companhias de capital fechado, como nos itens anteriores, se destacaram no atendimento às normas contábeis.

\section{Considerações Finais}

A partir da convergência das normas contábeis brasileiras ao padrão IFRS várias foram as mudanças ocorridas no âmbito da contabilidade brasileira. A principal delas decorre da necessidade de manter as informações contábeis livres de influências fiscais, logo, os demonstrativos tendem a representar, de fato, o patrimônio das entidades.

Diante do novo padrão contábil, a questão que direcionou este estudo relaciona-se com o grau de atendimento das novas normas quanto à evidenciação e divulgação das informações relativas aos ativos imobilizados e intangíveis e, para tanto, buscou-se nos normativos as principais regras para divulgação e apresentação das demonstrações contábeis.

Os resultados obtidos com as análises efetuadas nos 35 demonstrativos contábeis, de certa forma, são surpreendentes, pois, constata-se que mais de 50\% das entidades foram excluídas da análise em face de terem divulgado suas demonstrações contábeis de forma inadequada e sem as condições mínimas de análise; das 35 entidades objeto da pesquisa $62,86 \%$, foram auditadas e, daquelas que foram excluídas (18), 38,89\% também submeteram seus demonstrativos à auditoria independente; e os normativos referentes ao imobilizado e ao arrendamento mercantil apresentaram índices de cumprimento muito baixos, quando comparados com aqueles apresentados para o intangível e para o teste de recuperabilidade.

Ressalta-se, ainda, que a pesquisa aponta que as companhias de capital fechado se destacam no cumprimento das novas regras contábeis (IFRS) em relação às demais formas societárias analisadas, inclusive, sociedade de economia mista de capital aberto, a qual, em tese, deveria se destacar pelo grande rol de normas contábeis e de órgãos reguladores a que estão submetidas. Finalmente, tem-se que as normas contábeis internacionais aderidas pelo Brasil e editadas como práticas contábeis pelo Conselho Federal de Contabilidade (CFC), não estão sendo cumpridas adequadamente pelos profissionais de Contabilidade, bem como pela administração das entidades a qual é responsável pelas demonstrações, e também pelos profissionais de auditoria 
que, obrigatoriamente, precisam revisar tais demonstrações e recomendar o atendimento às normas vigentes.

Este trabalho contribui para os estudos voltados ao cumprimento dos normativos contábeis em IFRS, e chama a classe contábil para uma reflexão quanto à postura do profissional de contabilidade frente à nova normativa contábil.

Como sugestão para trabalhos futuros, recomenda-se sejam analisados demonstrativos contábeis submetidos à auditoria independente por empresas globais de auditoria conhecidas como Big Four, considerando a possibilidade de haver informações contábeis divulgadas em desconformidade com as novas práticas contábeis (IFRS).

\section{REFERÊNCIAS}

ALMEIDA, Marcelo Cavalcanti. Manual Prático de Interpretação Contábil da Lei Societária. São Paulo: Atlas, 2010.

ANTUNES, Maria Thereza Pompa; LEITE, Rafael Soares; GUERRA, Luiz Francisco. Divulgação das informações sobre ativos intangíveis e sua utilidade para avaliação de investimentos: um estudo exploratório baseado na percepção dos analistas de investimentos. In: CONGRESSO USP DE CONTROLADORIA E CONTABILIDADE, 7., 2007, São Paulo. Anais... São Paulo: USP, 2007. CD-ROM.

ANTUNES, Maria Thereza Pompa; SILVA, Luciana Cavalcante Pires de; SAIKI, Tatiana Galo. Evidenciação dos ativos intangíveis (capital intelectual) por empresas brasileiras à luz da Lei 11.638/07. In: CONGRESSO BRASILEIRO DE CUSTOS, 16., 2009, Fortaleza. Anais... Fortaleza: ABC, 2009. CD-ROM.

BRASIL. Lei Ordinária no ${ }^{\mathbf{~}}$ 6.404, de 15 de dezembro de 1976. Dispõe sobre as Sociedades por Ações. Disponível em: 〈http://www.planalto.gov.br/ccivil_03/leis/L6404compilada.htm〉. Acesso em 20 de nov. 2011.

BRASIL. Lei Ordinária nº 11.638, de 28 de dezembro de 2007. Altera e revoga dispositivos da Lei $\mathrm{n}^{\mathrm{0}}$ 6.404, de 15 de dezembro de 1976, e da Lei $\mathrm{n}^{\mathrm{0}}$ 6.385, de 7 de dezembro de 1976, e estende às sociedades de grande porte disposições relativas à elaboração e divulgação de demonstrações financeiras. Disponível em:

http://www.presidencia.gov.br/CCIVIL_03/_Ato2007-2010/2007/Lei/L11638.htm.>. Acesso em 20 de nov. 2011.

BRASIL. Lei Ordinária no . 11.941, de 27 de maio de 2009. Altera a legislação tributária federal relativa ao parcelamento ordinário de débitos tributários; concede remissão nos casos em que especifica; institui regime tributário de transição, e dá outras providências. Disponível em: http://www.planalto.gov.br/ccivil_03/_ato2007-2010/2009/lei/111941.htm. Acesso em 20 de nov. 2011.

COMITÊ DE PRONUNCIAMENTOS CONTÁBEIS. A Busca da Convergência da Contabilidade aos Padrões Internacionais: Programa de Trabalho - 2008 a 2010. 2008. Disponível em: www.cpc.org.br/pdf/convergencia_29dez2008.pdf. Acesso em 11/12/2011. 
CONSELHO FEDERAL DE CONTABILIDADE. Resolução CFC no $\mathbf{0}$ 1.177. Aprova a NBC TG 27 - Ativo Imobilizado. Brasília, 24 de julho de 2009. Disponível em www.cfc.org.br. Acesso em 25 de nov. 2011.

CONSELHO FEDERAL DE CONTABILIDADE. Resolução CFC nº 1.263. Aprova a ITG 10 - Interpretação sobre a Aplicação Inicial ao Ativo Imobilizado e à Propriedade para Investimento. Brasília, 10 de dezembro de 2009. Disponível em www.cfc.org.br. Acesso em 25 de nov. 2011.

CONSELHO FEDERAL DE CONTABILIDADE. Resolução CFC no $\mathbf{0}$ 1.292. Aprova a NBC TG 01 - Redução ao Valor Recuperável de Ativos. Brasília, 20 de agosto de 2010. Disponível em www.cfc.org.br. Acesso em 25 de nov. 2011.

CONSELHO FEDERAL DE CONTABILIDADE. Resolução CFC nº 1.303. Aprova a NBC TG 04 - Ativo Intangível. Brasília, 25 de novembro de 2010. Disponível em www.cfc.org.br. Acesso em 25 de nov. 2011.

CONSELHO FEDERAL DE CONTABILIDADE. Resolução CFC n⿳0. 1.304. Aprova a NBC TG 06 - Operações de Arrendamento Mercantil. Brasília, 25 de novembro de 2010. Disponível em www.cfc.org.br. Acesso em 25 de nov. 2011.

IUDÍCIBUS Sérgio de; MARTINS, Eliseu; GELBCKE, Ernesto Rubens; SANTOS, Ariovaldo dos. Manual de Contabilidade Societária: aplicável a todas as sociedades de acordo com as normas internacionais e do CPC. São Paulo: Atlas, 2010.

RECEITA FEDERAL DO BRASIL. Instrução Normativa SRF nº ${ }^{\circ}$ 162. Fixa prazo de vida útil e taxa de depreciação dos bens que relaciona. Brasil, 31 de dezembro de 1998. Disponível em http://www.receita.fazenda.gov.br/legislacao/ins/ant2001/1998/in16298.htm. Acesso em 28 de Nov. 2011.

REINA, Donizete; REINA, Diana Rossi Maximiano; ENSSLIN, Sandra Rolim; GALLON, Alessandra Vasconcelos; RONCHI, Suelen Haidar. Intangible assets: um estudo epistemológico da produção científica internacional no período de 1996 a 2008. In: 17 CONGRESSO BRASILEIRO DE CUSTOS, 16., 2009, Fortaleza. Anais... Fortaleza: ABC, 2009. CD- ROM.

SANTOS, Edilene Santana. Análise dos Impactos dos CPCs da Primeira Fase de Transição para o IFRS nas Empresas Abertas: um Exame Censitário dos Ajustes ao Resultado nas DFPs de 2008. XXXIV ENCONTRO da ANPAD, 2010, Rio de Janeiro. Anais. Rio de Janeiro: ANPAD, 2010, p. 1-3.

STICKNEY, Clyde P; WEIL, Roman L. Contabilidade Financeira: uma introdução aos conceitos, métodos e usos. 1. ed. - 3. reimpr. São Paulo: Atlas, 2008.

YAMAMOTO, Marina Mitiyo; SALOTTI, Bruno Meirelles. Informação contábil: estudos sobre a sua divulgação no mercado de capitais. São Paulo: Atlas, 2006.

YOKOI, Y. Padrão ameaçado. Revista Capital Aberto, São Paulo, v. 5, n. 56, p. 3438, abr. 2008. 